\title{
Ophthalmological assessment of children with neurofibromatosis type 1
}

\author{
Ismail Alpfidan • Yasar Sakarya • Sertan Goktas • \\ Muammer Ozcimen • Rabia Sakarya
}

Received: 25 July 2013 / Accepted: 7 August 2013 /Published online: 22 August 2013

(C) Springer-Verlag Berlin Heidelberg 2013

Dear Editor,

We read with great interest the article entitled "Ophthalmological assessment of children with neurofibromatosis type 1" by Cassiman et al. [1]. In their article, the authors reviewed the ophthalmological assessment of children with neurofibromatosis type 1 . The authors offered a complete clinical ophthalmological exam that included visual acuity, color vision, visual field, ocular motility, slit-lamp examination, and fundoscopy. They suggested optical coherence tomography (OCT) for the assessment of optic nerve fiber layer thickness in neurofibromatosis type 1 (NF1) patients with optic pathway gliomas (OPG).

OCT is a noninvasive diagnostic tool for the measurement of thickness of both retinal layers and optic nerve fiber layers. OCT also uses near-infrared reflectance (NIR) for imaging deeper structures such as the choroid. With the help of NIR, choroidal nodules in NF1 can be visualized as multiple bright, patchy areas [2]. NIR choroid findings of patients with NF1 were presented in a comprehensive article recently [2]. In this study, Viola et al. found that the prevalence of choroidal nodules detected by NIR in the overall population with NF1 was $82 \%$ and in the NF1 pediatric group was $71 \%$.

We think that NIR imaging of the choroid should be done in pediatric patients with NF1.

\section{References}

1. Cassiman C, Legius E, Spileers W, Casteels I. (2013) Ophthalmological assessment of children with neurofibromatosis type1. Eur J Pediatr doi: 10.1007/s00431-013-2035-2

2. Viola F, Villani E, Natacci F, Selicorni A, Melloni G, Vezzola D, Barteselli G, Mapelli C, Pirondini C, Ratigli R (2012) Choroidal abnormalities detected by near-infrared reflectance imaging as a new diagnostic criterion for neurofibromatosis 1. Ophthalmology 119:369375

I. Alpfidan $(\bowtie) \cdot$ Y. Sakarya $\cdot$ S. Goktas $\cdot$ M. Ozcimen $\cdot$ R. Sakarya Konya Training and Research Hospital, Eye Clinic, Konya, Turkey e-mail: ismail063@mynet.com 